\title{
Glycogen phosphorylase BB as a potential marker of cardiac toxicity in patients treated with anthracyclines for acute leukemia
}

\author{
Horacek $\mathrm{JM}^{1,2}$, Jebavy $\mathrm{L}^{1,2}$, Vasatova $\mathrm{M}^{3}$, Pudil $\mathrm{R}^{4}$, Tichy $\mathrm{M}^{3}$, Jakl $\mathrm{M}^{1,4}$, Maly $\mathrm{J}^{2}$ \\ Department of Internal Medicine, University of Defence, Faculty of Military Health Sciences in Hradec Kralove, \\ Czech Republic. horacek@pmfhk.cz
}

\begin{abstract}
Objectives: The aim of the presented study was to assess plasma glycogen phosphorylase BB (GPBB) concentrations in acute leukemia patients treated with anthracycline containing chemotherapy. Background: Anthracyclines represent the highest risk for development of cardiotoxicity. GPBB belongs to proposed biomarkers of cardiac injury with a very limited experience in this context.

Methods: Totally, 24 adult patients with acute leukemia were enrolled. Plasma GPBB concentrations were measured by ELISA at diagnosis (before chemotherapy), after first chemotherapy with anthracyclines and 6 months after the completion of treatment. The cut-off value for GPBB positivity was $10.00 \mu \mathrm{g} / \mathrm{L}$ as recommended by the manufacturer.

Results: Before chemotherapy, the mean plasma GPBB concentration was $5.25 \pm 3.81 \mu \mathrm{g} / \mathrm{L}$, increased above the cut-off in 1 patient (4.2\%). After the first chemotherapy, the mean GPBB was $6.61 \pm 5.54 \mu \mathrm{g} / \mathrm{L}$, positive in $7(29.2 \%)$ patients. Six months after treatment, the mean GPBB was $10.06 \pm 11.41 \mu \mathrm{g} / \mathrm{L}$, positive in $8(33.3 \%)$ patients. Six months after treatment, we found a significant correlation between elevation in GPBB and diastolic left ventricular dysfunction on echocardiography $(r=0.621 ; p<0.0001)$. The differences in plasma GPBB between healthy blood donors and patients treated for acute leukemia were statistically significant ( $p<0.01$ in all cases). Conclusion: Our results suggested that GPBB could become a potential biomarker for detection of acute and chronic cardiotoxicity associated with anthracycline containing chemotherapy. The predictive value for development of treatment-related cardiomyopathy in future is not clear and will be evaluated during the follow-up. Further studies are needed to define the potential role of GPBB and other biomarkers in the assessment of chemotherapy-induced cardiotoxicity (Ref. 21). Text in PDF www.elis.sk.

Key words: glycogen phosphorylase BB, cardiac toxicity, chemotherapy, anthracyclines, acute leukemia.
\end{abstract}

Cardiotoxicity induced by anticancer therapy remains an unresolved problem strongly impacting the quality of life and the overall survival of cancer patients. From cytostatics, anthracyclines represent the highest risk for development of cardiotoxicity (1-3). Echocardiography and electrocardiography are routinely used for monitoring of cardiotoxicity in oncology (4-6). However, the conventional methods are not sensitive enough to detect minor, subclinical and potentially reversible cardiac injury induced by anticancer therapy when an appropriate management could still improve the patient's outcome. Biomarkers of cardiac

${ }^{1}$ Department of Internal Medicine, University of Defence, Faculty of Military Health Sciences in Hradec Kralove, Czech Republic, ${ }^{2}$ Department of Medicine 2 - Clinical Hematology, University Hospital and Charles University, Faculty of Medicine in Hradec Kralove, Czech Republic, ${ }^{3}$ Institute of Clinical Biochemistry and Diagnostics, University Hospital and Charles University, Faculty of Medicine in Hradec Kralove, Czech Republic, and ${ }^{4}$ Department of Medicine 1, University Hospital and Charles University, Faculty of Medicine in Hradec Kralove, Czech Republic

Address for correspondence: JM Horacek, MD, PhD, Department of Internal Medicine, University of Defence, Faculty of Military Health Sciences, Trebesska 1575, CZ-500 01 Hradec Kralove, Czech Republic.

Phone: +420.495834520

Acknowledgement: The study was supported mainly by research projects MO 0FVZ0000503, RO 1011 (Czech Ministry of Defence) and partially by research project MZO 00179906 (Czech Ministry of Health). injury, especially cardiac troponins and natriuretic peptides, have been extensively studied for the early identification, assessment and monitoring of cardiotoxicity in oncology (7-13). Glycogen phosphorylase $\mathrm{BB}$ (GPBB) is a newer perspective marker of myocardial ischemia and necrosis, recently evaluated in the diagnostics and risk stratification of acute coronary syndromes (14-16). Experience with GPBB in the assessment of chemotherapy-induced cardiotoxicity is very limited (17).

The aim of our study was to assess plasma GPBB concentrations in acute leukemia patients treated with anthracycline containing chemotherapy to detect acute and chronic cardiotoxicity, and to compare plasma GPBB concentrations in acute leukemia patients to healthy blood donors.

\section{Methods}

Totally, twenty-four acute myeloid leukemia patients (mean age $47.2 \pm 11.6$ years; 13 males, 11 females) treated with three to six cycles of anthracycline containing chemotherapy were studied. The study was carried out with the ethics committee approval and in accordance with the relevant national guidelines. All patients gave an informed consent before they were included in the study. All patients had normal liver and renal functions during the study. Before chemotherapy, all patients had normal systolic 
and diastolic left ventricular (LV) function on echocardiography. We previously used biochip array (Randox, UK) for simultaneous testing of multiple cardiac biomarkers including GPBB (18). This time, we used a more precise ELISA method for a single quantitative detection of GPBB in plasma (Diagenics, Germany). Plasma GPBB concentrations were measured at the diagnosis (before chemotherapy), the day after first chemotherapy with anthracyclines (mean cumulative dose $125.4 \pm 27.6 \mathrm{mg} / \mathrm{m}^{2}$ ) and at 6 months after completion of treatment (mean total cumulative anthracycline dose $458.3 \pm 109.2 \mathrm{mg} / \mathrm{m}^{2}$ ). Twenty-four healthy blood donors were used as the control group. The cut-off value for GPBB positivity was $10.00 \mu \mathrm{g} / \mathrm{L}$, as recommended by the manufacturer. Echocardiographic assessment of systolic and diastolic LV function was performed before chemotherapy and at 6 months after treatment. Systolic LV dysfunction was defined as ejection fraction (LVEF) below $55 \%$. Diastolic LV dysfunction was defined as E/A inversion and E-wave deceleration time above $220 \mathrm{~ms}$ on the transmitral Doppler curve (impaired relaxation).

Statistical analysis was performed with the "Statistica" program. The analysis of variance test was used. Correlations were evaluated with normal and the Spearman correlation tests. The values were expressed as the mean $\pm \mathrm{SD}$. Probability values $\mathrm{p}<0.01$ and lower were considered statistically significant.

\section{Results}

Before chemotherapy, the mean plasma GPBB concentration was $5.25 \pm 3.81 \mu \mathrm{g} / \mathrm{L}$, increased above the cut-off in 1 patient $(4.2$ $\%)$. After the first chemotherapy, the mean GPBB was $6.61 \pm 5.54$ $\mu \mathrm{g} / \mathrm{L}$, positive in $7(29.2 \%)$ patients. Six months after treatment, the mean GPBB was $10.06 \pm 11.41 \mu \mathrm{g} / \mathrm{L}$, positive in $8(33.3 \%)$ patients. The difference between GPBB concentrations before chemotherapy and 6 months after treatment were statistical significant $(\mathrm{p}<0.01)$. The patient with GPBB positivity before chemotherapy $(18.55 \mu \mathrm{g} / \mathrm{L})$ had a higher GPBB positivity in the subsequent samples $(20.53$ and $32.16 \mu \mathrm{g} / \mathrm{L})$. Six months after treatment, we found a significant correlation between elevation in GPBB and diastolic LV dysfunction on echocardiography $(r=0.621 ; p<0.0001)$. No patient had manifestation of cardiotoxicity with symptoms of congestive heart failure during the study. In our cohort, we did not find a significant correlation between the total cumulative anthracycline dose and GPBB positivity or LV dysfunction on echocardiography after treatment.

The mean GPBB concentration in 24 healthy blood donors was $2.14 \pm 0.28 \mu \mathrm{g} / \mathrm{L}$ (range 1.81-3.05), negative in all subjects. The differences in plasma GPBB concentrations between healthy blood donors and patients treated for acute leukemia were statistically significant $(\mathrm{p}<0.01$ in all cases).

\section{Discussion}

GPBB belongs to perspective markers for an early detection of myocardial ischemia and necrosis, recently evaluated in the acute coronary syndrome setting (14-16, 19, 20). GPBB is a glycogenolytic enzyme providing glucose for heart muscle tissue. During glycogenolysis in ischemic tissue, GPBB is released from the sarcoplasmic reticulum into the cytoplasm and then into the circulation through the damaged cell membrane. GPBB is released into the circulation 2-4 hours after myocardial injury, returning to normal values within 24-36 hours of damage occurrence. In the acute coronary syndrome setting, GPBB is regarded as an early marker of cardiac injury due to an acute myocardial ischemia (21). However, the main mechanism of cardiac injury caused by anticancer therapy is mainly non-ischemic and prior cyclic exposition to anthracycline agents may play a role (chronic and late cardiotoxicity). Thus, it is difficult to estimate the kinetics of GPBB release from cardiomyocytes in this setting. The experience with this perspective biomarker in the assessment of cardiotoxicity induced by anticancer therapy is very limited $(17,18)$.

The results of our study suggested that GPBB could become a potential biomarker for the detection of an acute and chronic cardiotoxicity associated with anthracycline chemotherapy. Acute leukemia patients treated with anthracycline containing chemotherapy have significantly higher plasma GPBB concentrations in comparison with healthy subjects. Plasma GPBB concentrations at 6 months after treatment were significantly higher in comparison with the baseline values and correlated with diastolic LV dysfunction on echocardiography. A possible mechanism could be that prior cyclic exposition to anthracyclines causes metabolic changes and chronic minor injury to cardiomyocytes resulting in GPBB release into the bloodstream. In asymptomatic patients, these changes are considered as a sign of chronic subclinical cardiotoxicity. The predictive value for development of treatment-related cardiomyopathy in the future is not clear and will be evaluated during the follow-up. Based on our data, a larger prospective and multicenter study is needed to define the potential role of GPBB and other proposed biomarkers of cardiac injury in the assessment of cardiotoxicity induced by anticancer therapy.

\section{References}

1. Shan K, Lincoff AM, Young JB. Anthracycline-induced cardiotoxicity. Ann Intern Med 1996; 125: 47-58.

2. Jones RL, Swanton C, Ewer MS. Anthracycline cardiotoxicity. Expert Opin Drug Saf 2006; 5: 791-809.

3. Curigliano G, Mayer EL, Burstein HJ, Winer EP, Goldhirsch A. Cardiac toxicity from systemic cancer therapy: a comprehensive review. Prog Cardiovasc Dis 2010; 53: 94-104.

4. Ganz WI, Sridhar KS, Ganz SS, Gonzalez R, Chakko S, Serafini A. Review of tests for monitoring doxorubicin induced cardiomyopathy. Oncology 1996; 53: 461-470.

5. Altena R, Perik PJ, van Veldhuisen DJ, de Vries EG, Gietema JA. Cardiovascular toxicity caused by cancer treatment: strategies for early detection. Lancet Oncol 2009; 10: 391-399.

6. Urbanova D, Urban L, Mikuskova E, Klincova M, Mladosievicova B. Frequency-domain analysis of the signal-averaged electrocardiogram in hematological malignancies survivors. Bratisl Lek Listy 2010; 111: 144-149. 
$708-710$

7. Dolci A, Dominici R, Cardinale D, Sandri MT, Panteghini M. Biochemical markers for prediction of chemotherapy-induced cardiotoxicity: Systematic review of the literature and recommendations for use. Am J Clin Pathol 2008; 130: 688-695.

8. Mavinkurve-Groothuis AM, Kapusta L, Nir A, Groot-Loonen J. The role of biomarkers in the early detection of anthracycline-induced cardiotoxicity in children: a review of the literature. Pediatr Hematol Oncol 2008; 25: 655-664.

9. Eschenhagen T, Force T, Ewer MS et al. Cardiovascular side effects of cancer therapies: a position statement from the Heart Failure Association of the European Society of Cardiology. Eur J Heart Fail 2011; 13: 1-10.

10. Urbanova D, Urban L, Carter A, Maasova D, Mladosievicova B. Cardiac troponins - biochemical markers of cardiac toxicity after cytostatic therapy. Neoplasma 2006; 53: 183-190.

11. Gertz MA. Troponin in hematologic oncology. Leuk Lymphoma 2008; 49: 194-203.

12. Roziakova L, Bojtarova E, Mistrik M, Krajcovicova I, Mladosievicova B. Abnormal cardiomarkers in leukemia patients treated with allogeneic hematopoietic stem cell transplantation Bratisl Lek Listy 2012; 113: 159-162.

13. Lipshultz SE, Miller TL, Scully RE et al. Changes in cardiac biomarkers during doxorubicin treatment of pediatric patients with high-risk acute lymphoblastic leukemia: associations with long-term echocardiographic outcomes. J Clin Oncol 2012; 30: 1042-1049.
14. Peetz D, Post F, Schinzel $\mathbf{H}$ et al. Glycogen phosphorylase BB in acute coronary syndromes. Clin Chem Lab Med 2005; 43: 1351-1358.

15. Apple FS, Wu AH, Mair J et al. Committee on Standardization of Markers of Cardiac Damage of the IFCC. Future biomarkers for detection of ischemia and risk stratification in acute coronary syndrome. Clin Chem 2005; 51: 810-824.

16. Vasatova M, Tichy M, Horacek JM, Pudil R, Horakova L, Palicka V. Multi-marker approach in the diagnostics of cardiac diseases by protein biochip technology. Cas Lek Cesk 2009; 148: 591-596.

17. Cardinale D, Sandri MT. Role of biomarkers in chemotherapy-induced cardiotoxicity. Prog Cardiovasc Dis 2010; 53: 121-129.

18. Horacek JM, Vasatova M, Tichy M, Pudil R, Jebavy L, Maly J. The use of cardiac biomarkers in detection of cardiotoxicity associated with conventional and high-dose chemotherapy for acute leukemia. Exp Oncol 2010; 32: 97-99.

19. Rabitzsch G, Mair J, Lechleitner $P$ et al. Immunoenzymometric assay of human glycogen phosphorylase isoenzyme BB in diagnosis of ischemic myocardial injury. Clin Chem 1995; 41: 966-978.

20. Mair J. Glycogen phosphorylase isoenzyme BB to diagnose ischaemic myocardial damage. Clin Chim Acta 1998; 272: 79-86.

21. Bozkurt S, Kaya EB, Okutucu S, Aytemir K, Coskun F, Oto A. The diagnostic and prognostic value of first hour glycogen phosphorylase isoenzyme BB level in acute coronary syndrome. Cardiol J 2011; 18: 496-502.

Received February 12, 2012. Accepted August 18, 2013. 